\section{Surgical removal of non-age-related subfoveal choroidal neovascular membranes}

\begin{abstract}
Purpose To assess anatomical and visual results following the surgical removal of nonage-related subfoveal choroidal neovascular membranes.

Methods A retrospective study was carried out of 31 consecutive patients undergoing vitrectomy, parafoveal retinotomy and removal of subfoveal choroidal neovascular membranes that were either idiopathic or associated with multifocal choroiditis, high myopia, trauma or angioid streaks.

Results Visual acuity improved or remained the same in 25 eyes (81\%) after a mean followup of 10.1 months (range 3-37 months). Visual acuity improved by more than 2 lines of Snellen acuity in 5 eyes (16\%) and decreased by more than 2 lines in 2 eyes $(6 \%)$. There was no significant association between the final visual outcome and length of symptoms prior to surgery or pre-operative visual acuity. Atrophy of the retinal pigment epithelium and older age were associated with poor outcome. Membranes recurred in 11 eyes (35\%), and eyes with subfoveal blood prior to surgery were more likely to have recurrent membranes. Conclusions The results of surgical removal of non-age-related subfoveal neovascular membranes have been encouraging, but further studies of long-term outcome and of the natural history of individual conditions are required.
\end{abstract}

Key words Choroidal neovascularisation, Nonage-related macular degeneration, Surgical removal

Choroidal neovascularisation (CNV) is an important cause of visual loss in the United Kingdom. While extrafoveal CNV may respond to laser photocoagulation, the treatment options for subfoveal CNV are limited. ${ }^{1,2}$ Laser photocoagulation of the $\mathrm{CNV}$ beneath the fovea damages the overlying neurosensory retina, resulting in a central scotoma and immediate reduction of visual acuity. A decade ago, DeJuan and Machemer ${ }^{3}$ described a technique for removal of blood and $\mathrm{CNV}$ in 4 patients with advanced age-related macular degeneration (ARMD). They were able to remove the subfoveal $\mathrm{CNV}$ while minimising damage to the neurosensory retina and pigment epithelium. ${ }^{3}$ A number of similar reports followed, but the long-term visual results of surgical treatment of age-related CNV proved to be disappointing. ${ }^{4-8}$ On the other hand early reports of surgical removal of subfoveal CNV in younger people have been more encouraging. ${ }^{9}$

We present a review of 31 eyes that had nonage-related subfoveal CNV removed surgically.

\section{Patients and methods}

We retrospectively analysed the anatomical and functional results of 31 eyes of 31 consecutive patients that underwent vitrectomy, parafoveal retinotomy and removal of non-age-related subfoveal CNV. The surgery was performed by one of two experienced surgeons between 1994 and 1996.

Best corrected Snellen visual acuity was recorded pre-operatively and at all follow-up visits. A full ophthalmic examination was performed at each visit and included indirect ophthalmoscopy and slit lamp biomicroscopy.

Fluorescein angiograms and colour fundus photographs were obtained on all patients both pre- and post-operatively (4-6 weeks) and at any time at which recurrence of $\mathrm{CNV}$ was suspected.

There were 9 emmetropic eyes that had no drusen and no focal atrophic lesions. These were classified as idiopathic CNV. A further 10 eyes had multiple discrete choroidal punchedout scars in the posterior pole and were diagnosed as punctate inner choroidopathy or multifocal inner choroidopathy; these eyes were grouped together and were designated as multifocal choroiditis (MFC).

Eyes that had myopia of more than 6 dioptres were classified as 'highly myopic' (7 eyes). Other causes included pseudoxanthoma elasticum (PXE) associated with angioid streaks (1 eye), choroidal rupture due to blunt trauma (2 eyes), CNV developing after parafoveal laser photocoagulation (1 eye) and associated with sympathetic ophthalmitis (1 eye).
M. Eckstein

J.A. Wells

W. Aylward

Z. Gregor

Moorfields Eye Hospital

London, UK

Mr Z.J. Gregor, FRCOphth

Moorfields Eye Hospital City Road

London EC1V 2PD, UK 
Visual outcome was assessed and we attempted to define any predictors of final acuity and of visual change. We assessed final acuity (those who improved compared with those whose acuity remained the same or deteriorated) against: initial visual acuity, age (30 years or younger versus older than 30 years), duration of symptoms (distortion for more than 6 months prior to surgery versus less than 6 months), CNV recurrence (fluorescein angiographic evidence of leakage at any time up to final assessment), pre-operative subfoveal haemorrhage (visible blood on slit lamp biomicroscopy prior to surgery) and presumed retinal pigment epithelium (RPE) atrophy (absence of RPE on biomicroscopy and/or fluorescein angiography).

Statistical analysis to assess significance of variables was performed using the chi-squared test and an unpaired Student's $t$-test.

\section{Surgical technique}

A three-port pars plana vitrectomy was performed and the posterior hyaloid was separated by suction with a cutter or silicone tip extrusion needle. A $130^{\circ}$ angled 36 gauge subretinal pick was used to make a retinotomy close to the membrane, the site being chosen to avoid the papillomacular bundle. A macular detachment was induced by injecting balanced salt solution gently through the retinotomy or by elevating the edges of the retinotomy, allowing passive ingress of infusion fluid from the vitreous cavity. The subfoveal CNV was grasped with subretinal membrane forceps and delivered through the retinotomy. Haemostasis was ensured by raising the height of the infusion bottle during the removal. Intraocular tamponade was achieved with either $30 \%$ sulphur hexafluoride $\left(\mathrm{SF}_{6}\right)$ or air injection. No laser photocoagulation was applied to the retinotomy site. Patients remained in a face-down position for at least $24 \mathrm{~h}$ following surgery.

\section{Results}

Twenty-three patients were female and 8 were male; all were Caucasian. The mean follow-up was 10.1 months (range 3-37 months) and the mean age of patients at the time of surgery was 39.7 years (range 17-75 years). The mean duration of symptoms prior to surgery was 6.2 months (range 2-17 months). The clinical features of study cases are shown in Table 1.

\section{Anatomical results}

In 30 of the 31 cases the membrane appeared to be removed entirely at the time of surgery (Fig. 1). Four of the 7 myopic eyes had a small area of the RPE surrounding the $\mathrm{CNV}$ removed during surgical manipulation and a further 2 myopic eyes developed signs of RPE atrophy within 2 weeks of surgery. RPE appeared to be absent in 3 other non-myopic eyes

Table 1. Clinical features of cases

\begin{tabular}{|c|c|c|c|c|c|c|c|c|}
\hline $\begin{array}{l}\text { Case } \\
\text { no. }\end{array}$ & Aetiology & Sex & $\begin{array}{c}\text { Age } \\
\text { (years) }\end{array}$ & $\begin{array}{l}\text { Symptoms } \\
\text { (months) }\end{array}$ & $\begin{array}{c}\text { Pre-operative } \\
\text { acuity }\end{array}$ & $\begin{array}{l}\text { Final } \\
\text { acuity }\end{array}$ & $\begin{array}{l}\text { Follow-up } \\
\text { (months) }\end{array}$ & $\begin{array}{l}\text { Time to } \\
\text { recurrence }\end{array}$ \\
\hline 1 & Idiopathic & $\mathrm{F}$ & 58 & 10 & $6 / 24$ & $6 / 60$ & 6 & None \\
\hline 2 & Idiopathic & $\mathrm{M}$ & 57 & 5 & $6 / 24$ & $6 / 18$ & 13 & 3 months \\
\hline 3 & Multifocal choroiditis & $\mathrm{F}$ & 24 & 6 & $\mathrm{CF}$ & $6 / 18$ & 16 & None \\
\hline 4 & Multifocal choroiditis & $\mathrm{F}$ & 30 & 16 & $6 / 36$ & CF & 12 & None \\
\hline 5 & Multifocal choroiditis & $\mathrm{F}$ & 27 & 6 & $6 / 36$ & $6 / 9$ & 15 & None \\
\hline 6 & Myopia & $\mathrm{M}$ & 28 & 5 & $6 / 18$ & $6 / 12$ & 15 & None \\
\hline 7 & Idiopathic & $\mathrm{F}$ & 50 & 3 & $6 / 36$ & $1 / 60$ & 12 & 5 months \\
\hline 8 & Multifocal choroiditis & $\mathrm{F}$ & 20 & 5 & $1 / 60$ & $1 / 60$ & 3 & None \\
\hline 9 & Idiopathic & $\mathrm{F}$ & 46 & 5 & $2 / 60$ & $2 / 60$ & 6 & 1 month \\
\hline 10 & Myopia & $\mathrm{F}$ & 27 & 6 & $6 / 36$ & $6 / 36$ & 6 & 6 months \\
\hline 11 & Idiopathic & $\mathrm{F}$ & 70 & 6 & $6 / 60$ & CF & 4 & None \\
\hline 12 & Myopia & M & 49 & 5 & $6 / 60$ & $6 / 60$ & 24 & None \\
\hline 13 & Laser & $\mathrm{F}$ & 66 & 3 & $6 / 60$ & $6 / 24$ & 36 & None \\
\hline 14 & Idiopathic & $\mathrm{F}$ & 41 & 5 & $6 / 24$ & $6 / 24$ & 18 & 7 months \\
\hline 15 & Inflammatory & M & 60 & 3 & $3 / 60$ & $6 / 60$ & 37 & None \\
\hline 16 & Myopia & M & 25 & 2 & $1 / 60$ & CF & 6 & None \\
\hline 17 & Multifocal choroiditis & $\mathrm{F}$ & 17 & 4 & $1 / 60$ & $6 / 12$ & 9 & None \\
\hline 18 & Multifocal choroiditis & $\mathrm{F}$ & 24 & 9 & $6 / 36$ & $6 / 60$ & 6 & 1 month \\
\hline 19 & Multifocal choroiditis & $\mathrm{F}$ & 28 & 10 & $6 / 18$ & $6 / 36$ & 4 & 2 months \\
\hline 20 & Myopia & $\mathrm{F}$ & 30 & 17 & $1 / 60$ & $\mathrm{CF}$ & 3 & None \\
\hline 21 & Multifocal choroiditis & $\mathrm{F}$ & 30 & 5 & $1 / 60$ & $6 / 60$ & 3 & None \\
\hline 22 & Choroidal tear & $\mathrm{M}$ & 75 & 3 & $6 / 60$ & $2 / 60$ & 5 & 1 month \\
\hline 23 & Idiopathic & $\mathrm{F}$ & 46 & 6 & $6 / 60$ & $6 / 36$ & 12 & None \\
\hline 24 & Multifocal choroiditis & $\mathrm{F}$ & 21 & 7 & $6 / 60$ & $6 / 18$ & 7 & None \\
\hline 25 & Angioid & $\mathrm{F}$ & 47 & 3 & $6 / 24$ & $1 / 60$ & 7 & 2 months \\
\hline 26 & Idiopathic & $\mathrm{F}$ & 39 & 3 & $6 / 24$ & $6 / 9$ & 4 & None \\
\hline 27 & Myopia & $\mathrm{M}$ & 36 & 4 & $6 / 6$ & $6 / 60$ & 4 & None \\
\hline 28 & Myopia & $\mathrm{F}$ & 51 & 9 & $1 / 60$ & $6 / 36$ & 6 & None \\
\hline 29 & Choroidal tear & $\mathrm{M}$ & 57 & 14 & $6 / 60$ & $6 / 24$ & 6 & 3 months \\
\hline 30 & Idiopathic & $\mathrm{F}$ & 25 & 4 & $6 / 18$ & $6 / 36$ & 3 & 1 month \\
\hline 31 & Multifocal choroiditis & $\mathrm{F}$ & 28 & 6 & $6 / 60$ & $6 / 60$ & 6 & None \\
\hline
\end{tabular}




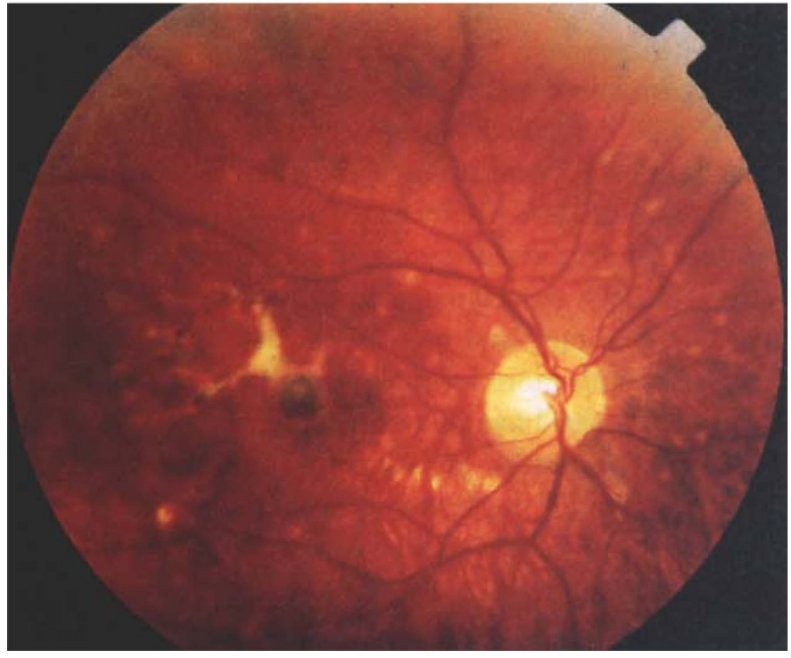

(a)

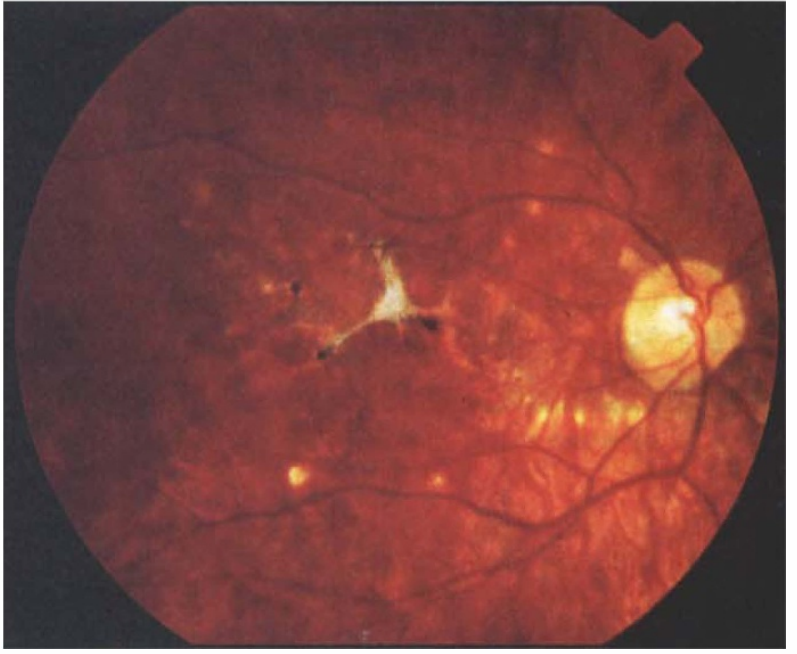

(b)

Fig. 1. Case 3. (a) Subfoveal membrane prior to surgery in a 24-year-old patient with multifocal choroiditis. Visual acuity CF. (b) Same patient 3 months following surgery. Visual acuity 6/18.

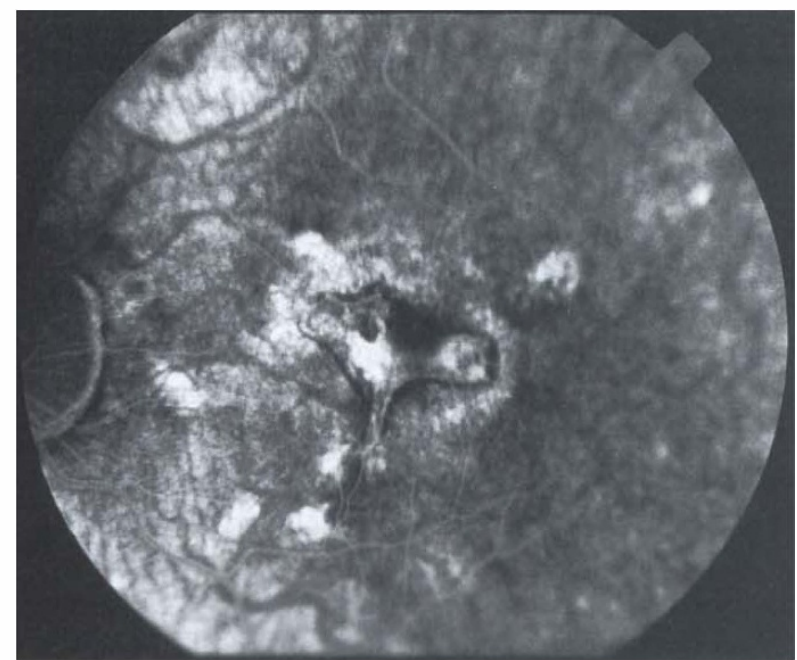

(a)

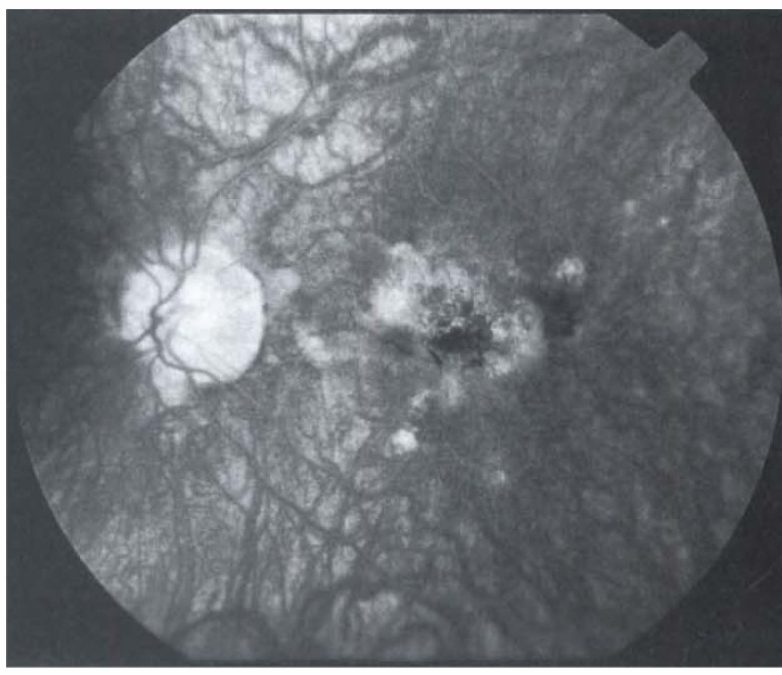

(b)

Fig. 2. Case 4. (a) Pre-operative fluorescein angiogram of a 30-year-old woman with multifocal choroiditis showing subfoveal CNV. (b) Postoperative fluorescein angiogram 1 month following surgical removal of subfoveal $\mathrm{CNV}$.

immediately following removal of CNV. A total of 15 $(48 \%)$ eyes had pigment epithelial atrophy by the end of the 3 month follow-up period (Fig. 2).

Recurrence. CNV recurred in 11 eyes (35.5\%) over the follow-up period. The mean time to recurrence after surgery was 3.1 months (range 1-7 months). CNV resulting from traumatic choroidal rupture ( 2 cases) and angioid streaks ( 1 case) all recurred in the early postoperative period. Recurrence was less likely in myopic eyes $(17 \%)$ and in eyes with MFC ( $25 \%)$. Two of the recurrent membranes were removed surgically but one recurred again within 3 weeks. Another two membranes (6\%) had laser photocoagulation; one recurred again.

Eyes that had visible subfoveal haemorrhage prior to surgery were more likely to have recurrences than those which had no subfoveal blood $(p=0.07)$. Atrophy of the RPE was not associated with an increased rate of recurrence $(p=0.32)$.

\section{Functional results}

Pre-operative visual acuity ranged from $6 / 9$ to counting fingers (CF) at $1 \mathrm{~m}$. Mean visual acuity was $6 / 24$ at the time of initial presentation and was $6 / 60$ immediately prior to surgery. Visual acuity after a mean postoperative follow-up of 10 months ranged from $6 / 9$ to $C F$ $(1 \mathrm{~m})$. Post-operative visual acuity was either better or the same (within 2 Snellen lines) as the pre-operative acuity in 25 eyes $(81 \%)$. Acuity following surgery improved by more than 2 Snellen lines in 5 eyes (16\%) and decreased by more than 2 lines in 2 eyes $(6 \%)$. Final acuity was greater than $6 / 18$ in 8 eyes $(26 \%)$ and $6 / 60$ or better in 22 eyes (71\%) (Fig. 3). Scattergrams of preoperative versus post-operative visual acuity are shown in Fig. 4. Points above the line of equality represent improved acuity following surgery.

The likelihood of an improvement in visual acuity at final follow-up compared with pre-operative acuity was not significantly associated with duration of symptoms 


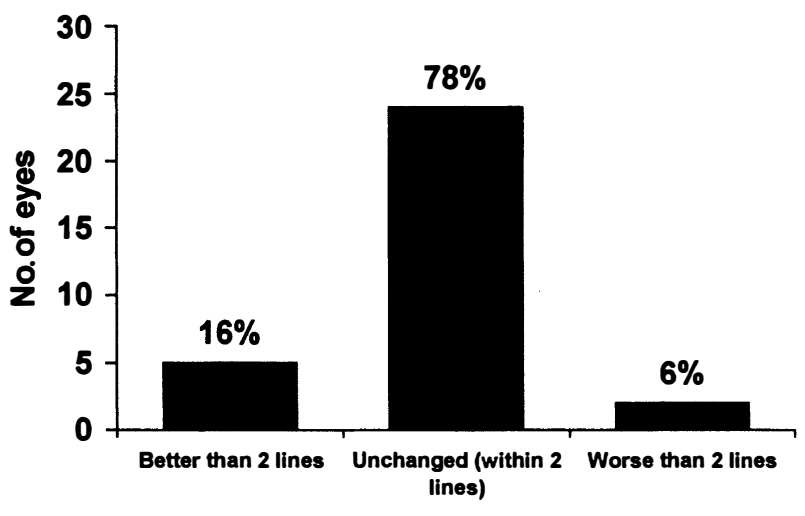

Fig. 3. Visual acuity at final follow-up compared with pre-operative visual acuity (Snellen lines).

prior to surgery $(p=0.32)$, sex $(p=0.47), \mathrm{CNV}$ recurrence $(p=0.61)$ or the presence of pre-operative subfoveal haemorrhage $(p=0.51)$. Pigment epithelial atrophy following surgery was associated with poor final visual acuity $(<6 / 36 ; p=0.05)$ and patients under 30 years old were more likely to improve their vision than older patients $(p<0.02)$.

\section{Complications}

There were no cases of retinal detachment or macular hole formation following surgery. Submacular bleeding during the procedure occurred in 4 cases $(13 \%)$ but all haemorrhages were controlled at the time of surgery by elevating the intraocular pressure. Two eyes $(6 \%)$ developed significant nuclear cataract within 6 months of surgery.
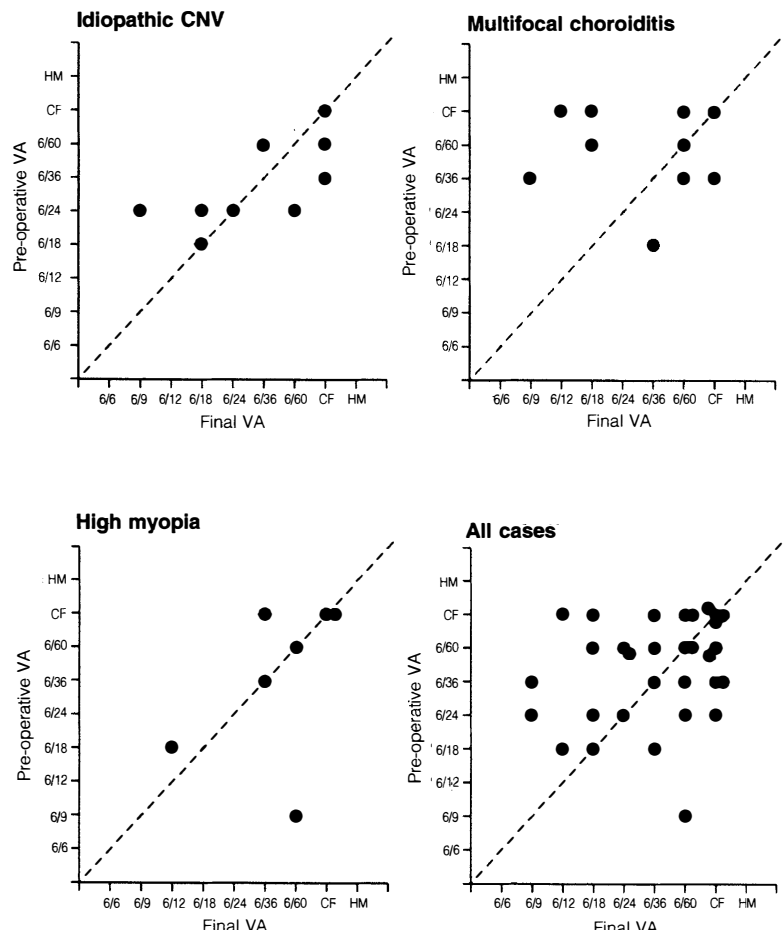

Fig. 4. Scattergrams of pre-operative versus post-operative visual acuity (VA) for all cases.

\section{Discussion}

Surgery for subfoveal choroidal neovascular membranes is now well described. ${ }^{9}$ In eyes with ARMD the results have been disappointing ${ }^{7}$ and may be no better than observation or laser photocoagulation. ${ }^{5}$ Gass ${ }^{10}$ explained the difference in visual outcome between eyes with subfoveal $\mathrm{CNV}$ associated with diffuse changes in Bruch's membrane and the RPE, such as in ARMD, and those eyes with more focal abnormalities, such as the presumed ocular histoplasmosis syndrome (POHS) and multifocal choroiditis. He suggested that there may be two distinct types of choroidal neovascular growth patterns. In type $1 \mathrm{CNV}$, such as occurs in ARMD, there are multiple ingrowth sites and the CNV develops beneath the RPE. In type $2 \mathrm{CNV}$, such as seen in multifocal choroiditis and POHS, there tends to be a single ingrowth site that proliferates anterior to the RPE in the subsensory retinal space. When type 2 membranes are removed surgically, the native RPE may be preserved and good visual function maintained. In contrast the removal of type 1 membranes is more likely to result in damage to the RPE and therefore result in significant visual loss.

The natural history of the conditions associated with non-age-related subfoveal $\mathrm{CNV}$ is not well documented. It is therefore difficult to compare the benefit of surgery with the natural history. Spontaneous involution of subfoveal CNV has been observed ${ }^{11}$ and Kleiner et al. ${ }^{12}$ reported that up to $14 \%$ of eyes with $\mathrm{POHS}$ and subfoveal CNV retained a visual acuity of $6 / 12$ or better over a median follow-up time of 3 years. Younger patients (under 30 years) with small membranes were more likely to preserve good vision over the follow-up period. In a natural history study of 68 eyes with MFC followed up over 3 years, $32 \%$ developed CNV and in $41 \%$ of these the vessels spontaneously regressed. ${ }^{13}$ Smaller areas of CNV (less than $100 \mu \mathrm{m}$ in diameter) were more likely to regress than areas greater than $200 \mu \mathrm{m}$ in diameter. In another series, 19 patients with idiopathic subfoveal CNV were followed up for a median of 87 months. Over $95 \%$ of eyes had stable or improved acuity over the follow-up period. ${ }^{14}$

No randomised clinical trials have been published, but in a study of 25 patients with POHS and subfoveal $\mathrm{CNV}^{15}$ laser photocoagulation did not appear to show any benefit over observation. In another small nonrandomised series comparing surgery, laser photocoagulation and observation, there was no significant difference in visual outcome between the three groups. ${ }^{16}$

In this small series we found few significant predictors of good visual outcome following surgery. Pigment epithelial atrophy following surgery was associated with a poor outcome and there was a trend for younger patients to have a better visual prognosis than older patients, but this may also be true of the natural history of the condition and not related to the surgery. A good initial acuity did not appear to increase the chance of a good final outcome. This suggests that if the 
Table 2. Visual outcome and recurrence rates compared in this and other studies by aetiology of subfoveal CNV

\begin{tabular}{|c|c|c|c|c|c|}
\hline \multirow[b]{2}{*}{ Study } & \multirow[b]{2}{*}{ No. of eyes } & \multicolumn{3}{|c|}{ Change in visual acuity } & \multirow[b]{2}{*}{$\begin{array}{c}\text { Recurrence } \\
\text { rate }\end{array}$} \\
\hline & & $\begin{array}{l}\text { Improved } \geqslant 3 \\
\text { Snellen lines }\end{array}$ & $\begin{array}{c}\text { Within } 3 \text { lines } \\
\text { or better }\end{array}$ & $\begin{array}{c}\text { Worse than } \\
3 \text { lines }\end{array}$ & \\
\hline \multicolumn{6}{|c|}{ Idiopathic CNV } \\
\hline Bottoni $^{21}$ & 6 & - & $66 \%$ & $33 \%$ & $33 \%$ \\
\hline Thomas $^{5}$ & 8 & $25 \%$ & $100 \%$ & 0 & $50 \%$ \\
\hline Adelberg $^{22}$ & 4 & $25 \%$ & $100 \%$ & 0 & $50 \%$ \\
\hline Our series & 9 & $11 \%$ & $77 \%$ & $11 \%$ & $44 \%$ \\
\hline \multicolumn{6}{|l|}{ Myopia } \\
\hline Bottoni $^{21}$ & 21 & - & $48 \%$ & $52 \%$ & $19 \%$ \\
\hline Thomas $^{5}$ & 10 & $10 \%$ & $80 \%$ & $20 \%$ & $20 \%$ \\
\hline Adelberg $^{22}$ & 5 & $20 \%$ & $100 \%$ & 0 & $20 \%$ \\
\hline Our series & 7 & $14 \%$ & $71 \%$ & $29 \%$ & $14 \%$ \\
\hline \multicolumn{6}{|c|}{ Multifocal choroiditis } \\
\hline Thomas $^{5}$ & 9 & $33 \%$ & $90 \%$ & $10 \%$ & $11 \%$ \\
\hline Olsen $^{23}$ & 6 & $50 \%$ & $100 \%$ & 0 & $66 \%$ \\
\hline Adelberg $^{22}$ & 2 & $50 \%$ & $100 \%$ & 0 & - \\
\hline Our series & 10 & $40 \%$ & $80 \%$ & $20 \%$ & $20 \%$ \\
\hline \multicolumn{6}{|l|}{ POHS } \\
\hline Thomas $^{5}$ & 67 & $34 \%$ & $83 \%$ & $17 \%$ & $37 \%$ \\
\hline Thomas $^{18,19}$ & 117 & $40 \%$ & $81 \%$ & $19 \%$ & $44 \%$ \\
\hline Berger $^{17}$ & 63 & $35 \%$ & $44 \%$ & $21 \%$ & $38 \%$ \\
\hline \multicolumn{6}{|c|}{ Choroidal rupture } \\
\hline Gross $^{24}$ & 3 & 0 & $100 \%$ & - & - \\
\hline Our series & 2 & 0 & $100 \%$ & - & $100 \%$ \\
\hline
\end{tabular}

presenting visual acuity of patients with subfoveal CNV is good, it may be better to observe the evolution of CNV initially and perform surgery if the vision deteriorates. There are conflicting data in eyes with POHS; in one series, eyes that had a pre-operative vision of $6 / 60$ or worse were more likely to improve than eyes that had a vision of $6 / 30$ or better. ${ }^{17}$ This contrasts with a series which reported that eyes with a pre-operative acuity of better than $6 / 30$ had a significantly better post-operative visual acuity than eyes with pre-operative acuity of $6 / 60$ or worse. ${ }^{5}$ The visual acuity 3 months following surgery in this series appeared to be a reliable predictor of the final visual outcome. ${ }^{18}$

In our series, eyes with MFC had a mean improvement of 1.5 Snellen lines of acuity compared with myopic eyes, which had a mean decrease of 0.6 lines of acuity. However, the relatively small numbers in the different aetiological groups makes it difficult to draw strong conclusions. The poor visual outcome in the myopic eyes may have been associated with the progressive atrophy of the RPE that was observed in 6 of the 7 highly myopic eyes with CNV. This is probably because in high myopia the changes in Bruch's membrane are rather diffuse, perhaps analogous to the widespread nature of other conditions such as AMD. On the other hand, post-inflammatory CNV such as in MFC are associated with more focal changes in the subretinal tissues and the surrounding Bruch's membrane may be relatively normal.

The overall recurrence rate in this study (35\%), was similar to that in other published series (Table 2) and to the recurrence rate following laser photocoagulation. ${ }^{2}$ Many series suggest that idiopathic CNV and CNV associated with POHS and MFC are more likely to recur than CNV associated with high myopia. In Melberg et al.'s cohort, ${ }^{19} 44 \%$ of 117 eyes with POHS developed recurrence between 2 weeks and 28 months after surgery. The median time to recurrence was 3 months and $84 \%$ of recurrences occurred within 6 months of surgery. ${ }^{19}$ Nearly half of these recurred again after a second procedure. In that series, as in ours, there was no association between visual outcome and CNV recurrence. In our study, the presence of subfoveal haemorrhage prior to surgery was associated with a higher incidence of recurrence. The haemorrhage may be a marker for a more active neovascular process and systemic steroids have been advocated to reduce this activity prior to surgery. ${ }^{20}$

It is still uncertain whether the long-term outcome following surgery or laser photocoagulation is better than the natural history of the condition. Because of the small size of this series and because patients were divided into different aetiological groups with small numbers, it is not possible to draw strong conclusions. Surgical removal of subfoveal CNV can, however, improve visual function in selected cases, particularly if the pigment epithelium is spared, and surgery remains an important treatment option.

\section{References}

1. Macular Photocoagulation Study Group. Krypton laser photocoagulation for idiopathic neovascular lesions: results of a randomised clinical trial. Arch Ophthalmol 1990;108:832-7.

2. Macular Photocoagulation Study Group. Argon laser photocoagulation for neovascular maculopathy: five year results from randomised clinical trials. Arch Ophthalmol 1991;109:1109-14. 
3. DeJuan E, Machemer R. Vitreous surgery for hemorrhagic and fibrous complications of age-related macular degeneration. Am J Ophthalmol 1988;105:25-9.

4. Thomas MA, Grand MG, Williams DF, Lee CM, Pesin SR, Lowe MA. Surgical management of subfoveal choroidal neovascularization. Ophthalmology 1992;99:952-68.

5. Thomas MA, Dickinson JD, Melberg NS, Ibanez HE, Dhaliwal RS. Visual results after surgical removal of subfoveal choroidal neovascular membranes.

Ophthalmology 1994;101:1384-96.

6. Ormerod LD, Puklin JE, Frank RN. Long-term outcomes after the surgical removal of advanced subfoveal neovascular membranes in age-related macular degeneration.

Ophthalmology 1994;101:1201-10.

7. Lambert HM, Capone A Jr, Aaberg TM, et al. Surgical excision of subfoveal neovascular membranes in age-related macular degeneration. Am J Ophthalmol 1992;113:257-62.

8. Berger AS, Kaplan HJ. Clinical experience with the surgical removal of subfoveal neovascular membranes: short-term postoperative results. Ophthalmology 1992;99:969-75.

9. Thomas MA, Kaplan HJ. Surgical removal of subfoveal neovascularization in the presumed ocular histoplasmosis syndrome. Am J Ophthalmol 1991;111:1-7.

10. Gass JD. Biomicroscopic and histopathologic considerations regarding the feasibility of surgical excision of subfoveal neovascular membranes. Am J Ophthalmol 1994;118:285-98.

11. Campochiaro PA, Morgan KM, Conway BP, Stathos J. Spontaneous involution of subfoveal neovascularization. Am J Ophthalmol 1990;109:668-75.

12. Kleiner RC, Ratner CM, Enger C, Fine SL. Subfoveal neovascularization in the ocular histoplasmosis syndrome: a natural history study. Retina 1988;8:225-9.

13. Brown J Jr, Folk JC, Reddy CV, Kimura AE. Visual prognosis of multifocal choroiditis, punctate inner choroidopathy, and the diffuse subretinal fibrosis syndrome. Ophthalmology 1996;103:1100-5.

14. Ho AC, Yannuzzi LA, Pisicano K, DeRosa J. The natural history of idiopathic subfoveal choroidal neovascularization. Ophthalmology 1995;102:782-9.
15. Fine SL, Wood WJ, Isernhagen RD. Laser treatment for subfoveal neovascular membranes in ocular histoplasmosis syndrome: results of a pilot randomised clinical trial. Arch Ophthalmol 1993;111:19-20.

16. Submacular Surgery Trials Planning Group. Visual acuity outcomes following submacular surgery, laser photocoagulation, or observation of subfoveal choroidal neovascularisation. Invest Ophthalmol Vis Sci 1995;36:S9.

17. Berger AS, Conway M, Del Priore LV, et al. Submacular surgery for subfoveal choroidal neovascular membranes in patients with presumed ocular histoplasmosis [see comments]. Arch Ophthalmol 1997;115:991-6.

18. Holekamp NM, Thomas MA, Dickinson JD, Valluri S. Surgical removal of subfoveal choroidal neovascularisation in presumed ocular histoplasmosis. Ophthalmology 1997;104:22-6.

19. Melberg NS, Thomas MA, Dickinson JD, Valluri S. Managing recurrent neovascularization after subfoveal surgery in presumed ocular histoplasmosis syndrome. Ophthalmology 1996;103:1064-7.

20. Flaxel CJ, Owens SL, Mulholland B, Schwartz SD, Gregor ZJ. The use of corticosteroids for choroidal neovascularisation in young patients. Eye 1998;12:266-72.

21. Bottoni F, Airaghi P, Perego E, Ortolina S, Carlevaro G, De Molfetta V. Surgical removal of idiopathic, myopic and agerelated subfoveal neovascularization. Graefes Arch Clin Exp Ophthalmol 1996;234(Suppl 1):S42-50.

22. Adelberg DA, Del Priore LV, Kaplan HJ. Surgery for subfoveal membranes in myopia, angioid streaks, and other disorders. Retina 1995;15:198-205.

23. Olsen TW, Capone A, Sternberg P, Grossniklaus HE, Martin DF, Aaberg TM. Subfoveal choroidal neovascularisation in punctate inner choroidopathy. Ophthalmology 1996;103:2061-9.

24. Gross JG, King LP, de Juan E Jr, Powers T. Subfoveal neovascular membrane removal in patients with traumatic choroidal rupture. Ophthalmology 1996;103:579-85. 